\title{
The Research of the University Student E-knowledge Management Model Under Blended Learning
}

\author{
Qian $\mathrm{Ao}^{1, \text { a }}$,Hua Liu ${ }^{2, \mathrm{~b}}$ \\ ${ }^{1}$ Computer Network Center of ShangRao Normal University, ShangRao Normal University, \\ ShangRao, 334001, China \\ ${ }^{2}$ Computer Network Center of ShangRao Normal University, ShangRao Normal University, \\ ShangRao, 334001, China

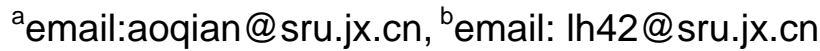

Keyword: Blended Learning; Knowledge Management; Social Software

\begin{abstract}
The definition of blended learning, the connotation of knowledge management and the characteristics of social software was analyzed in the paper.And the internal relation between college students' knowledge management and Social Software under blended learning environment is expounded . With this relation, the mode construction of network model of college students' knowledge management is explored, So that to promote college students utilizing the common social software to manage knowledge and improving their learning ability.
\end{abstract}

\section{Introduction}

According to the 31th statistics report of China Internet network information center, so far to the end of December 2012, the number of Chinese Internet users reached 564 million, Internet penetration rate is $42.1 \%$, especially those who have college degree or above, the ratio of Internet user in college students is close to saturation [1].They are high information literacy ,using the internet frequently and high dependent on network. So to college students, internet and computer are not only a technical tool ,but more a lifestyle based on modern information and communication technologies.

College students are keen on recording micro blog, participating Wikipedia, share photo and video, mutual discussion and comment .they are known as "I- generation”, "a generation grew up under Internet the environment". They are tend to more self-centered, and more willing to interaction rather than passive action[2]. In this sense, computer and internet is becoming a necessary tool of college students study, life and entertainment. With the arrival of web2.0, social software with users as the core emerges in endlessly, and greatly enriched the network life of college students. So it is feasible that college students' knowledge management become networked under blended learning environment.

\section{A. The definition of blended learning}

With "90s after" entering college school who is a new generation growing up with Internet, college teacher face severe challenges in the education concept, teaching organization mode and teaching tool application. These students are the digital, survival in network and thinking with help electronic products generation. In this context, the blended learning is becoming an important form in digital campus. Course website, video class, online communication etc,have gradually new elements of college teaching .And they are known and accepted by many college teachers[3].With the rapid development of higher education Informatization, blended learning is changing the way of higher education learning with amazing speed.There are many different results and opinions about the definition of blended learning by different scholars and different fields. A view of He Kekang who is a professor in Peking University is" the key of blended learning is that combines the advantage of traditional learning and network learning”;Li Jiahou , a professor of Shanghai normal university thinks" the so-called blended learning is that all the elements is optimized selected and combination to achieve the teaching goal ".

In the paper ,the definition of blended learning is a optimization integrated learning 
solution combined the advantages of the variety learning ,.Compare with the traditional face to face teaching ,a significant progress is the application of information technology. Blended learning combined modern information technology and traditional teaching ,so as to gain a better teaching effect. It not only a simple form mixed of face to face learning and online learning, but according to actual situation ,combined the advantage of the traditional face to face leaning and the digital technology advantage of network learning (E-learning ), a learn method under network environment.

\section{B. The connotation of college students' knowledge management}

With the arrival of knowledge economy, the update of knowledge and the generation of new knowledge are more astonishing speed. In recent years ,the concept of knowledge management gradually permeate in the field of education, learners through a personal knowledge management, effective use of knowledge, enhance the value of knowledge, and share with others to growth of new knowledge, achieve the goal of fast access and update knowledge. As the information technology, network technology, communication technology and the rapid development of computer technology, college students, can gain and use knowledge more and more rich, but new problems coming, prominently displays in : too much information and complicated improper; Information has nothing to do and not suitable for serious; Information is scattered and distribution. These problems increased the difficult of college student acquiring, accumulating knowledge and innovation. Therefore, personal knowledge management is becoming increasingly important. It is an effective way to solve this problem by personal knowledge management.

The meaning of the college students' knowledge management regard as: college students knowledge management is a process that college students effectively learn, manage, innovate knowledge by use of information technology and network environment.Manage knowledge, namely, learn knowledge, share knowledge, create knowledge, as shown in Figure 1.

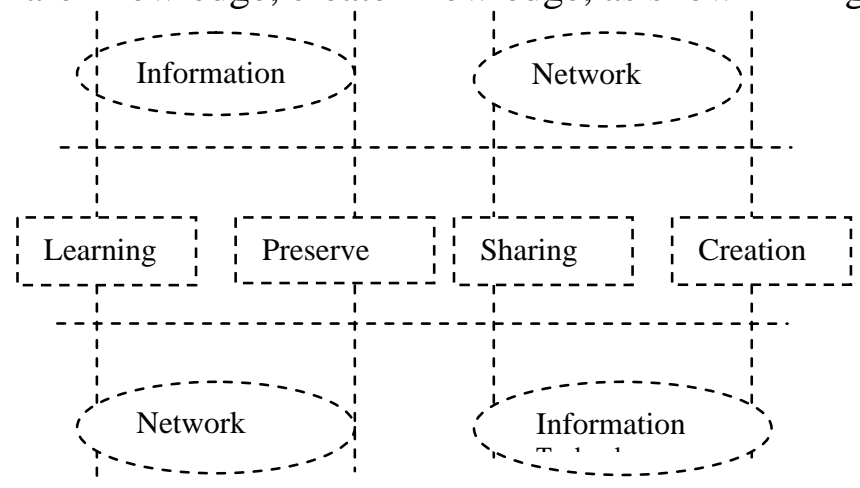

Fig.1. Knowledge management under the network environment

\section{Management tools in network era-social software}

Social software is emerging in recent years. As network software and tools, it provides convenience for knowledge management, become an important factor of promoting knowledge management. Social software can promote the establishment of user social network, encourage the formation of collective cooperation behaviors and relationships, and contribute the common development of individual and group knowledge. Social software provides an extremely convenient learning support for college students, make the acquisition of knowledge more convenient and fast, and make the conversion between learning and knowledge supplement each other.

Social software pay more attention to the dynamic process of share knowledge, innovation and communication. Also, it can use social software to share knowledge resources, to explore the process and interpersonal interaction. In the whole process of knowledge management, the college students not only a recipient, also a innovator and constructor. College students can build knowledge social relationship network by social software. 


\section{Construct the network model of college students' knowledge management under blender learning using social software}

\section{A. The theoretical basis (digital age learning theory)}

In the network environment, new knowledge produces continuously, college students face the challenges of the new information learning environment, particularly learn to networked knowledge management.Connectionist is a theory that describe learning in the Internet age how to happen, and explore the integration of the chaos theory ,network theory, complexity theory and the self organizing theory. It thinks that learning has the following characteristics: chaos , sustainability (emphasized on learning knowledge for demand), and co-creation(everyone is both producers and consumer) ,complexity (multiple ,integrated), specialization, continuous shelving certainty .[4]

The principles of connectionist are that:

- Learning is a network forming process of connecting information sources.

- Knowledge can reside in non-human appliance, and technology can promote leaning.

- The ability of found connected, recognize patterns and generate meaning among the field, the ideas and the concepts, is the core of individual skills today. Maintenance the epochal character of knowledge is purpose of all connectionist activity. The process of making decision is learning.

\section{B.Construct college students' knowledge management model using social software}

Base on theory of digital age learning theory - Connectionist, social software theory, and according to the knowledge management function of social software, construct the network model of college students ' knowledge management, which let the learners consciously study, knowledge internalization, collaboration, communication, sharing of resources in the process of daily Internet use.In the digital age ,college students manage individuals rapid growth knowledge through the use of computer technology, network technology and modern information services, and integrate the most important information to their-self into the individuals framework of knowledge base. [5]. College students personal knowledge management can be interpreted it is the management activities that using knowledge management tools ,which has the corresponding function such as search, storage, and communication tools of, knowledge acquisition, to organization, communicate, share ,innovate knowledge, and integrate and complement their information resources on the basis of the personal demand, gradually establish and improve the personal knowledge, enhance personal adaptation, survival ability and competition ability .

The typical social software such as RSS, wikis, blogs have the advantage of "zero cost", "zero technique". It can help college students to convenient, fast and efficient manage individual knowledge though social software and web 2.0 environment. It also provide many practical tools to help them convert the mass, random, fragmented information into the available and scalable one that system can use.The applications of these feasible social software can considered that it is a management process of learning, keeping, sharing, creating knowledge on the personal demand and desire[6], as shown in Figure 2: 


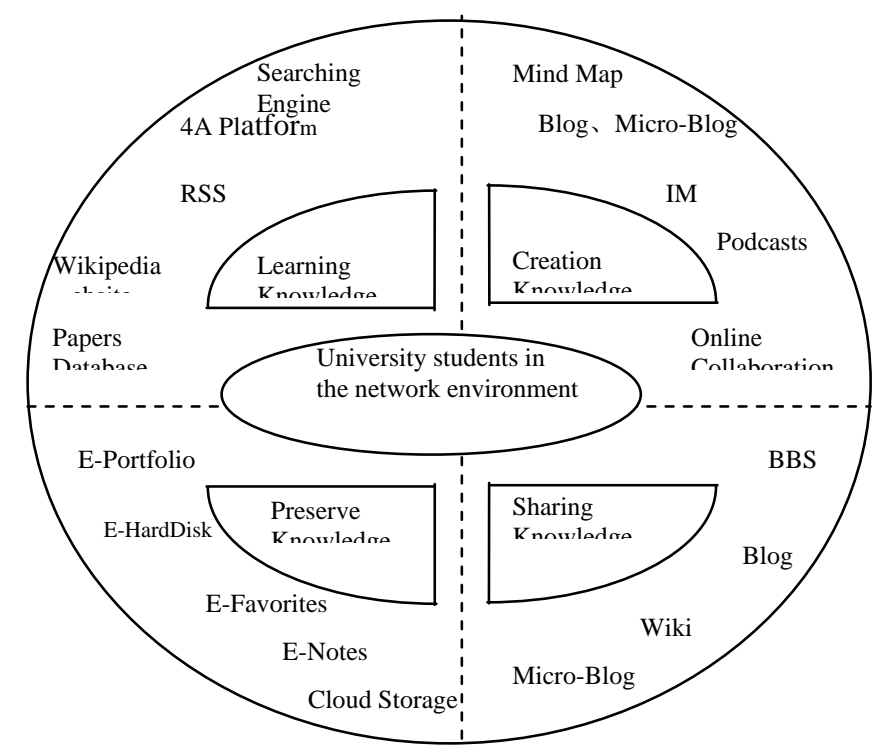

Fig.2. College students network model of knowledge management under blended learning

\section{CONCLUSION}

The author considers that knowledge management is both personal behavior and social activities. The network model of College students' knowledge management under Blended learning is an attempt to improve the knowledge application and innovation ability. It a key ability in the era of knowledge economy. It a continuous process .So college students should continuous use kinds of efficient knowledge management tools to maintain personal knowledge database, to add, delete, modify and update resources, share ,communicate with others, and even create knowledge. The process of management is can gradually improve the personal knowledge structure, enhance manage knowledge ability.

But college students have the problem that self-control and self-discipline ability is weak. It should properly supervise by teacher and society when they use society software.

\section{References}

[1] China Internet DevelopmentStatisticsReport [EB/OL].[2013-01-15] http://www.cnnic.cn/hlwfzyj/ hlwxzbg/hlwtjbg/201301/t20130115_38508.htm

[2] GuoDongZhao.Practical Research on University E-campus \& E-learning[M]. Peking University Press 2012:204.

[3] Willian Horton.E-Learning by Design [M]. Education and Science Press 2006:331.

[4] WenzhengYang,CaipingXiong. The Common development of cognitive and social system based on social software [J]. E-education Research 2011,(11):23-27.

[5] Zhiting Zhu. Xiaoqing Gu Knowing Knowledge [M]. East China Normal University Press 2009:100

[6] XuefengWang,YuetingWang. Personal Knowledge Management Model for Network Learning based on Social Software Mash-up Technology [J]. Modern Educational Technology,(3):8-12. 